\title{
Peranan Zeolit dalam Peningkatan Kesuburan Tanah Pasca Penambangan
}

\author{
${ }^{1}$ Ida Nursanti dan ${ }^{2}$ Nida Kemala \\ ${ }^{1}$ Program Studi Agroteknologi, Fakultas Pertanian Universitas Batanghari \\ ${ }^{2}$ Program Studi Agribisnis, Fakultas Pertanian Universitas Batanghari \\ J1. Slamet Riyadi, Broni Jambi, 36122. Telp. +62741 60103 \\ 1e-mail korespondensi : ida_unbari@yahoo.co.id
}

\begin{abstract}
Post-mining soils have poor chemical and physical properties and have very low fertility rates. The study aims to determine the best dose of zeolite in order to improve soil fertility after mining as a planting medium. The experiment was carried out experimentally by giving zeolites $(Z)$ and 3 treatment levels, namely: $Z 0=$ without zeolites, $Z 1=$ zeolites $100 \mathrm{~g}, Z 2=$ zeolites $200 \mathrm{~g}$. There were 3 replications, so 9 unit experiments were obtained. The final analysis of research on soil chemistry consists of; Available $P$, total $N$, K-exs, C-organic and CEC, $p H$. Data analysis of the diversity of characteristics of post-mining soil types is presented in tabular form and discussed descriptively. Provision of 200 grams zeolite of $10 \mathrm{~kg}$ post-mining land (equivalent to 20 tons $\mathrm{Ha}^{-1}$ of zeolite) and incubated for eight weeks can increase soil $\mathrm{pH}$, total $N$, $K$-dd, available $P$ and CECsoil.
\end{abstract}

Keywords : Zeolites and post-mining soils

Abstrak. Tanah pasca penambangan memiliki sifat kimia dan fisik yang kurang baik serta memiliki tingkat kesuburan yang sangat rendah. Penelitian bertujuan mengetahui menentukan dosis zeolit terbaik agar dapat memperbaiki kesuburan tanah pasca penambangan terkait sebagai media tanam. Percobaan dilakukan secara eksperimen dengan pemberian zeolit $(\mathrm{Z})$ dan 3 taraf perlakuan yaitu :Z0= tanpa zeolit, Z1 = zeolit $100 \mathrm{~g}, \mathrm{Z2}$ = zeolit $200 \mathrm{~g}$. Terdapat 3 ulangan, sehingga diperoleh 9 unit percobaan. Analisis akhir penelitian terhadap kimia tanah terdiri dari; $\mathrm{P}$ tersedia, $\mathrm{N}$ total, $\mathrm{K}$-dd, $\mathrm{C}$-organik dan $\mathrm{KTK}$, $\mathrm{pH}$. Analisis data keragaman karakteristik jenis tanah pasca penambangan disajikan dalam bentuk tabel dan dibahas secara deskriptif. Pemberian zeolit 200 gram per $10 \mathrm{~kg}$ tanah pasca tambang (setara 20 ton zeolit per Ha) dan diinkubasi selama delapan minggu dapat meningkatkan $\mathrm{pH}$ tanah, $\mathrm{N}$-total, $\mathrm{K}$-dd, $\mathrm{P}$ tersedia dan KTK tanah.

Kata kunci : Zeolit dan tanah pasca penambangan.

\section{PENDAHULUAN}

Kesuburan tanah pada lahan reklamasi tambang batubara muda tergolong sangat rendah. Kandungan unsur hara makro yaitu N, P dan K semuanya bekisar sangat rendah di lapisan atas dan lapisan bawah. Reaksi tanah masam serta kapasitas tukar kation sangat rendah. Umumnya topografi pada areal bekas penambangan yang telah direklamasi berupa berbukit dengan lereng $>8 \%$ kecuali pada areal galian yang ditutup rata-rata datar, berombak dan landau (Purnamayani, 2016).

Salah satu bahan yang dapat digunakan untuk memperbaiki lahan penambangan adalah menggunakan bahan pembenah tanah. Zeolit adalah bahan pembenah tanah yang merupakan mineral alam bermuatan negatif, dapat dinetralkan oleh logam-logam alkali atau alkali tanah, memiliki pori-pori terisi ion-ion $\mathrm{K}, \mathrm{Na}, \mathrm{Ca}, \mathrm{Mg}$ dan molekul $\mathrm{H}_{2} \mathrm{O}$, sehingga memungkinkan terjadinya pertukaran ion dan pelepasan air secara bolak-balik. Selain sebagai penukar kation, zeolit juga berfungsi sebagai penyerap kation-kation yang dapat menyebabkan pencemaran lingkungan seperti $\mathrm{Pb}, \mathrm{Al}, \mathrm{Fe}, \mathrm{Mn}, \mathrm{Zn}$, dan $\mathrm{Cu}$. Adanya zeolit tersebut dapat mengurangi pencemaran lingkungan (Oste et al., 2002).

Penggunaan zeolit mampu menyerap logam berat pada limbah perairan seperti $\mathrm{Pb}, \mathrm{Hg}$ dan $\mathrm{Cd}$ (Vaulina, 2002). Zeolit dapat mengabsorpsi $\mathrm{CO}_{2}, \mathrm{H}_{2} \mathrm{~S}$ dan $\mathrm{NH}_{3}$, serta mengurangi tercucinya unsur $\mathrm{N}$. Pemanfaatan zeolit di bidang pertanian selama ini adalah: bahan untuk meningkatkan kualitas pupuk organik, bahan campuran untuk membuat pupuk lambat tersedia, pembenah tanah dan pengontrol cadangan air. Selanjutnya dijelaskan juga bahwa pemberian zeolit hendaknya dikombinasikan dengan pupuk organik (Jabri, 2008). 
Pemberian zeolit sekitar $0,5 \mathrm{~kg}$ pada kompos 0,216 $\mathrm{m} 3$ dengan proses dekomposisi selama 3 minggu dapat meningkatkan $\mathrm{pH}$ kompos, ketersediaan $\mathrm{N}, \mathrm{P}$ dan $\mathrm{K}$ serta menurunkan nisbah $\mathrm{C} / \mathrm{N}$ kompos (Susanti dan Panjaitan, 2010). Penambahan zeolit sebanyak 5\% pada tanah pasir meningkatkan populasi bakteri dan populasi jamur (Djajadi et al., 2010). Zeolit pada lumpur minyak bumi yang diinkubasi selama 6 minggu dengan dosis 10\% dapat menurunkan kadar logam berat seng (Zn) 40\%, kandungan minyak dan poliaromatik hidrokarbon (PAH) masing-masing sebesar $23,18 \%$ dan $14,16 \%$ serta berpengaruh terhadap jumlah jamur dan bakteri (Dhayat, 2011).

Mineral zeolit dapat meningkatkan fosfat dan mengurangi pencucian $\mathrm{P}$ pada kompos karena zeolit memiliki kapasitas retensi P yang tinggi serta sebagai adsorben dan slow release nutrisi (Gu et al., 2011). Pemberian tanah ultisol $25 \%$ dan zeolit $200 \mathrm{~g}$ pada media gambut dapat mempengaruhi pertumbuhan bibit kakao secara signifikan terutama pada tinggi tanaman, bobot kering tajuk, kadar $\mathrm{N}$ daun dan kadar $\mathrm{P}$ daun (Nursanti, 2017). Sebagai bahan pembenah tanah, jumlah zeolit yang perlu diberikan sekitar 10-20 ton/ha. Zeolit sebagai bahan pembenah tanah dapat meningkatkan KTK tanah yang dalam jangka panjang dapat mempertahankan kualitas tanah. (Suwardi, 2000). Penelitian Rahmawati (2006) menyatakan bahwa perlakuan zeolit memberikan pengaruh nyata terhadap kadar air kapasitas lapang, $\mathrm{P}$ tersedia, serapan $\mathrm{P}$, berat kering tanaman dan tinggi tanaman.

\section{METODE PENELITIAN}

Penelitian dilakukan dengan menggunakan sampel tanah pada area pasca penambangan batubara di Desa Tanjung Pauh Kabupaten Muaro Jambi. Penelitian berlangsung selama 5 bulan yaitu dari bulan April sampai September 2019.

Bahan dan alat yang digunakan dalam pelaksanaan penelitian zeolit $\left(\mathrm{Na}_{2} \mathrm{AI}_{2} \mathrm{Si}_{3} \mathrm{O}_{10} .2 \mathrm{H}_{2} \mathrm{O}\right)$ powder 60 mesh jenis klinoptilolit dari Gunung Kidul Jogyakarta, pupuk kandang, tanah pasca penambangan, polybag diameter $15 \mathrm{~cm}$ atau berat tanah $10 \mathrm{~kg}$, dan alat-alat tulis. Tanah dari lapangan dikeringanginkan, kemudian dipecah agar lebih halus, lalu diaduk secara merata dan diayak dengan ayakan bermata saring 0,5 $\mathrm{x} 0,5 \mathrm{~cm}$ dan ditimbang $10 \mathrm{~kg}$ polybag ${ }^{-1}$. Kemudian tanah tersebut dimasukkan ke dalam polybag.

Percobaan dilakukan secara eksperimen dengan pemberian zeolit (Z) dan 3 taraf perlakuan yaitu :Z0= tanpa zeolit, Z1 = zeolit $100 \mathrm{~g}, \mathrm{Z2}=$ zeolit $200 \mathrm{~g}$. Terdapat 3 ulangan, sehingga diperoleh 9 unit percobaan. Setelah media diinkubasi selama 8 minggu maka diambil sampelnya untuk dianalisis. Masing-masing perlakuan diambil satu sampel tanah, berat untuk setiap sampel adalah $0,5 \mathrm{~kg}$. Selanjutnya sampel dikirim ke laboratorium tanah untuk dianalisis.

Analisis akhir penelitian terhadap kimia tanah terdiri dari; P tersedia (Bray-I), N total (Kjeldahl), Kdd (titrasi NH4Oac.pH 7), C-organik (Walkley Black) dan KTK (titrasi NH4Oac.pH 7), pH H2O (1:1). Analisis data keragaman karakteristik jenis tanah pasca penambangan disajikan dalam bentuk tabel dan dibahas secara deskriptif.

\section{HASIL DAN PEMBAHASAN}

Hasil penelitian memeperlihatkan bahwa C-org tanah setelah pemberian zeolit tetap pada posisi sangat rendah, $\mathrm{N}$-total meningkat setelah pemberian zeolit $200 \mathrm{~g}$ tiap $10 \mathrm{~kg}$ tanah dari $0,11 \%$ pada posisi rendah menjadi $0,28 \%$ posisi sedang, K-dd mengalami peningkatan setelah pemberian zeolit $200 \mathrm{~g}$ tiap $10 \mathrm{~kg}$ tanah dari 0,10 pada kriteria sangat rendah menjadi $0,40(\mathrm{cmol}(+) \mathrm{kg}-1)$ kriteria sedang, $\mathrm{P}$ Bray meningkat setelah pemberian zeolit $200 \mathrm{~g}$ tiap 10kg tanah dari 9,20 menjadi $16,65\left(\mathrm{mg} \mathrm{kg}^{-1}\right)$, KTK juga mengalami peningkatan dari $15,21(\mathrm{cmol}(+) \mathrm{kg}-1)$ kriteria rendah menjadi $23,04(\mathrm{cmol}(+) \mathrm{kg}-1)$ kriteria sedang setelah pemberian zeolit $200 \mathrm{~g}$ tiap 10kg tanah, sedangkan $\mathrm{pH}$ tanah dari masam menjadi agak masam setelah pemberian $200 \mathrm{~g}$ zeolit (Tabel 1). 
Tabel 1. Kandungan C-organik (\%), N-total (\%), P Bray I (mg kg $\left.{ }^{-1}\right)$, K-dd (cmol(+)kg-1) dan KTK $\left(\mathrm{cmol}(+) \mathrm{kg}^{-1}\right)$ serta $\mathrm{pH}$ tanah pasca penambangan sebagai pengaruh pemberian zeolit dan tanpa zeolite (inkubasi 8 minggu).

\begin{tabular}{ccccccc}
\hline Zeolit(g/polybag) & C-org. & N-total & K-dd & P Bray I & pH & KTK \\
\hline 0 & $0,16 \mathrm{sr}$ & $0,11 \mathrm{r}$ & $0,10 \mathrm{sr}$ & $9,20 \mathrm{r}$ & $4 \mathrm{~m}$ & $15,21 \mathrm{r}$ \\
100 & $0,80 \mathrm{sr}$ & $0,22 \mathrm{~s}$ & $0,20 \mathrm{sr}$ & $14,21 \mathrm{r}$ & $5,8 \mathrm{am}$ & $17,39 \mathrm{~s}$ \\
200 & $0,73 \mathrm{sr}$ & $0,28 \mathrm{~s}$ & $0,40 \mathrm{~s}$ & $16,65 \mathrm{~s}$ & $6,0 \mathrm{am}$ & $23,04 \mathrm{~s}$ \\
\hline
\end{tabular}

Huruf kecil pada setiap kolom menunjukkan kriteria penilaian sifat tanah (LPT, 1983) $\mathrm{r}=$ rendah, $\mathrm{s}=$ sedang, $\mathrm{t}=$ tinggi, $\mathrm{st}=$ sangat tinggi, $\mathrm{m}=$ masam dan $\mathrm{am}=$ agak masam

Peningkatan $\mathrm{pH}$ oleh zeolit dimungkinkan karena kation-kation basa yang terdapat pada zeolit seperti $\mathrm{Ca} \mathrm{K}$ dan $\mathrm{Mg}$ dapat dipertukarkan dengan ion $\mathrm{H}^{+}$dan $\mathrm{Al}^{3+}$. Zeolit dapat menyangga $\mathrm{pH}$ tanah, tanah masam dapat dinetralisir karena zeolit bersifat tidak masam $(\mathrm{pH} 7,2)$ dan dapat mengadsorpsi $\mathrm{Al}$ dan $\mathrm{Fe}$ penyebab kemasaman tanah serta melepaskan kation-kation basa seperti $\mathrm{Ca}, \mathrm{Mg}$ dan $\mathrm{K}$. Endro (2008) menjelaskan bahwa zeolit merupakan mineral yang dapat menetralisir $\mathrm{pH}$ tanah.

Peningkatan kandungan hara seperti N-total, $\mathrm{P}$ tersedia berasal dari proses mineralisasi yang membebaskan unsur-unsur tersebut ke tanah. Selain itu kandungan hara berasal dari decomposisi bahan organik dan unsur yang diadsorpsi oleh zeolit. Vaulina (2002) menjelaskan, jika kadar N dalam larutan tanah kurang maka $\mathrm{N}$ yang diadsorpsi oleh zeolit akan dilepas secara perlahan. Hasil penelitian Ermadani et al. (2002) menunjukkan bahwa pemberian asam-asam organik (humat, oksalat dan sitrat) dapat meningkatkan P-tersedia dan P-total tanah zeolit akan dilepas secara perlahan. Li et al. (2000) menjelaskan bahwa pertukaran kation zeolit pada dasarnya adalah fungsi dari derajat substitusi silika oleh aluminium dalam struktur kristal zeolit. Semakin banyak jumlah aluminium menggantikan posisi silika maka semakin banyak muatan negatif yang dihasilkan, sehingga KTK zeolit akan semakin tinggi. Menurut Ersoy dan Celik (2003), zeolit merupakan bahan katalis yang memiliki sifat stabilitas dan selektivitas dalam meningkatkan proses perombakan senyawa organik dari berat molekul besar (polimer) menjadi senyawa organik sederhana (monomer) yang didukung oleh sifat medan elektrostatik zeolit dan peran struktur ruang pori zeolit. Selain itu zeolit merupakan bahan pengadsorpsi, penetralisir $\mathrm{pH}$ dan mudah melakukan pertukaran ion. Proses adsorpsi oleh zeolit sebagai adsorbent terhadap ion-ion yang dapat menyebabkan kemasaman tanah $\left(\mathrm{Al}^{3+}, \mathrm{Fe}^{3+}\right.$ dan $\left.\mathrm{H}^{+}\right)$terjadi karena ada gaya tarik menarik antar ion yang memiliki perbedaan keelektronegatifan yang rendah (Gaya Van Der Waals) dan didukung oleh keberadaan rongga di dalam zeolit yang berperan sebagai perangkap.

\section{KESIMPULAN}

Pemberian zeolit 200 gram per $10 \mathrm{~kg}$ tanah pasca tambang batubara (setara 20 ton zeolit per Ha) dan diinkubasi selama delapan minggu dapat meningkatkan $\mathrm{pH}$ tanah, N-total, K-dd, P tersedia dan KTK tanah.

\section{DAFTAR PUSTAKA}

Dhayat. N.R. 2011. Bioremediasi lumpur minyak bumi dengan zeolit dan mikroorganisme serta pengujiannya terhadap tanaman sengon ( Paraserianthes falcataria ). http://www.google.com. (diakses 23 Desember 2017).

Djajadi. Helianto.B dan Hidayah,N. 2010. Pengaruh media tanam dan frekuensi pemberian air terhadap sifat fisik, kimia dan biologi tanah serta pertumbuhan jarak pagar. Jurnal Littri. 16(2): 64-69.

Endro.K. 2008. Optimasi pemanfaatan zeolit alam dari gunung kidul untuk reduksi kadar cesium dalam limbah radioaktif. Prosiding Seminar Nasional Penelitian dan Pengelolaan Perangkat Nuklir, Batan, Yogyakarta 
Ersoy.B dan Celik.M.S. 2003. Effect of hydrocarbon chain length on adsorption of cationic onto clinoptilolite. Journal Clays and Clays Minerals. 51: 172-180.

Ermadani dan Arsyad.A.R. 2007. Perbaikan beberapa sifat kimia tanah mineral masam dengan pemanfaatan limbah cair pabrik kelapa sawit. J. Lembaga Penelitian Universitas Jambi Seri Science 09(2): $99-105$.

Gu, Z., F. Buyuksonmez, S. Gajaraj, and N. Edward. 2011. Adsorption of phosphate by goethite and zeolite: effects of humic substances from green waste compost. ProQuest Agriculture Journales. 19(3): 197-204.

Jabri.A. 2008. Kajian metode penetapan kapasitas tukar kation zeolit sebagai pembenah tanah untuk lahan pertanian terdegradasi. Jurnal Standardisasi. 10(2): 56-69.

Li. Z, Allesi. D dan Allen. L. 2000 . Influence of quartenary ammonium of sorption of selected metal cations onto clinoptilolite zeolite. Journal of Environmental Quality. 31: 1106- 1114

Nursanti. I. (2017). Tanggap Bibit Kakao Terhadap Media Tanam Gambut dan Ultisol Serta Zeolit. Jurnal Media Pertanian ISSN 2503-1279. 2(2) : 47 - 54.

Oste.L.A, Lexmond.T.M, and Riemsdijk.V. 2002. Metal immobilization in soils using synthetic zeolites. Journal of Environmental quality. Proquest Research Library.31: 813-821.

Purnamayani.R. 2016. Karakteristik kimia tanah lahan reklamasi tambang batubara di Provinsi Jambi. Prosiding Seminar Nasional Lahan Suboptimal. 20-21 Oktober 2016.Palembang.

Rahmawati. 2006. Pengaruh pemberian Zeolit dan Kompos TKS Terhadap Beberapa Sifat Fisik dan Serapan P Tanaman Jagung (Zea mays L.) Pada Tanah Typic Paleudult. Universitas Sumatera Utara. Medan.

Suwardi. 2000. Pemanfaatan zeolit sebagai media tumbuh tanaman hortikultura. Departemen Tanah, Fakultas Pertanian IPB, Prosiding. Temu Ilmiah IV. PPI. Tokyo, Jepang.

Susanti.P.D dan Panjaitan.S. 2010. Manfaat zeolit dan rock phosphat dalam pengemposan limbah pasar.Prosiding Standardisasi 4 Agustus 2010.Banjarmasin. p. 1-20.

Vaulina. E. 2002. Potensi zeolit alam sebagai absorban logam-logam berat pada limbah perairan. Majalah Ilmiah Universitas Jenderal soedirman. Purwokerto. 2(28): 1-8. 